THE JOURNAL OF TEACHING ENGLISH FOR SPECIFIC AND ACADEMIC PURPOSES Vol. 9, No 1, 2021, pp. 51-59

UDC: $811.111: 159.922 .72 \quad$ https://doi.org/10.22190/JTESAP2101051T

Review research paper

\title{
NARRATIVE-BASED MEDICAL WRITING: AN EMP CASE STUDY
}

\author{
Irina Torubarova, Anna Stebletsova
}

Voronezh Burdenko State Medical University, Voronezh, Russia

\begin{abstract}
The article discusses a case study employing medical writing for the development of skills, attitudes and values that are essential for the healthcare worker's identity. The emphasis is made on empathy, communication skills and communicative tolerance. The authors argue that these attitudes can be enhanced in the academic curriculum of medical universities. The possible way to improve personal qualities essential for the future career of a medical worker is through narrative-based medical writing, which can be implemented in the course of the English for Specific (Medical) Purposes $(E S(M) P)$ course. The 13-week course 'Narrative-based medical writing' designed and performed at Voronezh Medical University involved 60 undergraduate students. The participants had to complete 10 to 13 writing assignments describing patients' experience of a disease. The key findings of the study have demonstrated a more competent usage of reflective writing techniques, a higher level of empathy manifestation and communicative tolerance comparing to the baseline measurements. These results support the idea that EMP with a narrative-based writing module can make an essential contribution to the development of communicative tolerance and empathic manifestation, thereby enabling the development of the crucial professional attitudes of a healthcare practitioner.
\end{abstract}

Key words: narrative-based medical writing, EMP, empathy, communicative tolerance, communication skills

\section{INTRODUCTION}

Narrative, in its general sense, is a text which describes people and events. It has been existing since the beginning of the humankind: it is manifested in various forms of oral or written genres - epic poems, legends, sagas, fairy tales, novels. Narrative in terms of linguistics is commonly defined as "a spoken or written account of connected events; a story". (Oxford English Dictionary). Russian "Brief Literature Encyclopedia (Kratkaya literaturnaya entsiklopediya)" (Чудаков, 1968) describes "narrative" as an independently created story about a set of interrelated events presented to the reader or listener as a sequence of words or images.

Narrative-based medicine as a science was originated comparatively recently, at the end of the $20^{\text {th }}$ century. Rita Charon, Patricia Mary "Trisha" Greenhalgh, Brian Hurwitz,

Submitted September $30^{\text {th }}, 2020$, accepted for publication November $9^{\text {th }}, 2020$

Corresponding author: Irina Torubarova, Voronezh Burdenko State Medical University, Voronezh, Russia

|E-mail: torubarova69@mail.ru

(C) 2021 by University of Niš, Serbia | Creative Commons License: CC BY-NC-ND 
Howard A. Brody are stated to be its founders. The rise of interest towards this branch of science is closely connected with essence of the doctor-patient relation: a patient needs to tell his story full of suffering and emotions, a doctor needs to adequately listen to the patient and his story and transform it into a medical history for its further beneficial use in the clinical environment.

"Narrative medicine has been variously defined, but at its broadest it includes developing a "sense of story" in practitioners, an appreciation for and understanding of the fact that, from a certain perspective, medicine is a story-telling enterprise." (Shapiro, 2012: 309) In this regard it is possible to consider narrative-based medicine as a medical approach that utilizes people's narratives in clinical practice, research, and education as a way to promote healing. It aims to address the relational and psychological dimensions that occur in tandem with physical illness, with an attempt to deal with the individual stories of patients. In doing this, narrative medicine aims not only to validate the experience of the patient, but also to encourage creativity and self-reflection in the physician. (Charon \& Hermann, 2012)

"Narrative-based medicine (NBM) is the application of narrative ideas to the practice of medicine". (Zaharias, 2018: 177) As stated, narrative-based medicine is intended to improve that imbalance between the patients' dissatisfaction with the quality of provided healthcare service resulting from their expectations addressing doctors' attitude and behavior, on the one side, and doctors' dissatisfaction with their working environment including "difficult patients", stressful work etc., on the other side. This obviously marks a close interplay between most crucial interpersonal components of effective healthcare management (Mercer et al., 2002), namely, empathy and good communication, representing a multidisciplinary subject of health, communication and applied linguistics research.

Empathy is generally attributed to attitudes ranking high among essential healthcare qualities and values as it has a significant impact on doctor-patient cooperation. Research on clinical communication has demonstrated that empathy is able to enhance the doctorpatient relationship and improve both patient and doctor satisfaction. (Mercer et al., 2002) There is certain evidence proving interdependence between the patient's awareness of the doctor's empathy and the patient's ability to adhere to therapy, i.e. patient's compliance with treatment which is known to provide positive clinical outcomes. (Mercer et al., 2002)

Communication can be regarded as a natural environment of healthcare. We share a traditional view that good communication skills are crucial for a medical practitioner and are subject for professional training alongside with other medical skills and techniques. Communication skills' development is being closely scrutinized recently as patient-centred approach is gaining more popularity in doctor-patient relationship. Good communication skills are obviously a beneficial tool for creating comfortable environment for all healthcare discourse participants. Being an empathic communicator is a role model for any healthcare worker willing to implement patient-centred approach in their daily practice. (Choudhary \& Gupta, 2015; King \& Hoppe, 2013)

Furthermore, medical researchers exploring doctor-patient relations report on communicative tolerance. (Bashkin, 2015; Sidorenko et al., 2019; Torubarova, 2014) Communicative tolerance is said to determine successful interpersonal interaction and, as a result, successful professional socialization of future medical workers. The term "communicative tolerance" consists of two definitions - "communicative" and "tolerance". "Communicative" means "willing to talk and give information to other people", "tolerance" means "the quality of being willing to accept or tolerate somebody/something, especially opinions or behaviour that you may not agree with, or people who are not like you". 
(Oxford learner's dictionaries) Thus, it may be concluded that "communicative tolerance" is a feature describing the relationship between people, which is determined by personal meaningful, conflict-free manner of human behavior. A person with a high level of communicative culture is characterized as balanced, able to communicate with different people, which results in a psychologically comfortable environment for cooperation. In contrast, the lack of communicative tolerance or its low level prevents successful communication in the social, professional or household sphere.

Even though much research has been done on communication, communicative tolerance and empathy with regard to effective clinical practice, they all remain a challenge for higher medical education in Russia and globally. "Medical students and GP trainees are taught the importance of good communication skills, patient-centredness, and the biopsychosocial and "holistic" paradigms, and about addressing the patient's ideas, concerns, and expectations. Despite this, patients frequently complain that doctors do not listen, they appear disinterested, they interrupt, they make assumptions, and they do not address patient concerns. Doctors defend themselves by complaining about difficult patients, the pressures of patient numbers and time, and the travesties of consumer medicine. Nevertheless, from a patient perspective, doctors have lost sight of what matters". (Zaharias, 2018: 177).

\subsection{Narrative-based reflective practice as a way to develop physician identity}

Patients' dissatisfaction is a clear indicator that there is still a gap between 'a bench' and 'a bedside' in regard to good communication practice, and higher medical education has yet to find pedagogical solutions to address these issues. The global demand for better clinical communication and respect for patients' needs may lead to a faster shift to humanities, e.g. Applied Linguistics (ESP, EMP) as additional sources of communication skills and professional values' development.

Medical educators turn to various pedagogical practices that may contribute to the development of personal attitude essential for future healthcare professionals. One of these approaches "involves narrative reflective practice as a way to develop physician identity". (Clandinin et al., 2010: 1) This is exactly the area where linguists have a substantial toolkit of educational tasks, assignments and scenarios that can be used for both empathy and communication development.

Rita Charon, a proponent of the narrative-based medicine approach, and her successors work "from a narrative view of experience" asking medical students "to write stories of their experiences with patients", stories that "are critical to the care of their patient that do not belong in the hospital chart but have to be written somewhere." (Clandinin et al., 2010: 2)

"Physicians too have felt the need to tell stories about their patients, themselves, and the ties that bind them, and medical education has incorporated writing about patients (and themselves) as a valuable educational tool to help learners develop critical thinking, challenge facile assumptions, think more deeply about patients and themselves in relation to their patients, become more aware of their own and patients' emotions, and ward off cynicism and disillusionment." (Shapiro, 2012: 309) Obviously, narrative writing can also be considered as a way of developing critical thinking and reflection, which appear to be the key professional characteristics of future health workers. 
According to Charon and Coulehan, narrative medicine (Charon, 2006) includes the following elements:

- attention (being fully present in listening to, observing, and attending to the patient);

- representation (how the patient is represented-in writing and in telling-to colleagues, learners, the patients themselves and their family, and to the self of the physician);

- affiliation (commitment to adopting a position of compassionate solidarity with the patient's suffering, empathy for the patient's perspective, and advocacy for the patient's needs. (Coulehan, 2009)

Our hypothesis is that these elements can become integral components of narrative writing module within the academic curriculum of a medical university. As Russian medical universities' undergraduate programs involve a compulsory EMP course, EMP teachers may use language practice for the benefit of narrative medicine. So, the aim of our case study is to prove that narrative writing assignments can be used in the language classroom for the development of professional attitudes and values of future healthcare practitioners.

\section{MATERIALS AND METHODS}

Our case study 'Narrative-based medical writing' was designed and performed as a part of the English for Medical Purposes (EMP) course at Voronezh Medical University in 2018-2019 academic year. It lasted for 13 weeks. The inclusion criteria were voluntary participation and topic vocabulary competence. The topic vocabulary competence was developed prior to the case study and was based on the second module of the EMP course.

The second module of the basic EMP course involves 'Diseases' - language topics introducing most common diseases' vocabulary, i.e. definitions, etiology signs, symptoms, diagnosis, treatment, risks and prevention. There was also a topic 'Pain', which introduced and drilled the vocabulary on types and characteristics of pain including its severity and association with particular diseases. So, by the time of 'Narrative-based medical writing' was introduced, undergraduate students had already become familiar with the basic vocabulary on diseases which was allowed them to feel free while expressing their thoughts rather than struggle with terminology. Besides, they had listening exercises on doctor-patient consultations, and were involved in nursing clinical experience "on sites", so the students were also aware of common medical worker-patient roles in the interaction.

The 'Narrative-based medical writing' consisted of 10-13 writing assignments. An assignment had an instruction which asked students on behalf of patients suffering from a disease to write what they thought and felt about their diseases. The instruction went as follows:

'Imagine you are a patient suffering from a disease. Describe in detail what you feel and think about your condition, how it started or the worst attack of the illness. Choose any disease you have studied in Module II or describe the one of your own choice'.

The participation in the case study was voluntary. There were 60 undergraduate students who participated in the study. They were all 2-year students of General Medicine Department. The following diseases were chosen: diabetes mellitus, herniated disc, bronchial asthma, psoriasis, Crohn's disease, allergies, gout. Participants were free to choose genre and style of their texts. They were not limited to any word count. Students could also use 
information about the disease from any reliable sources such as articles from the journals, encyclopedia, textbooks, books of reference in medicine/pharmacy, etc.

The assessment included writing skills marking and professional attitudes' evaluation. The latter was done with a test measuring empathic abilities and communicative tolerance. Language errors were marked and discussed with each student individually, recommendations for text improvement and development were given to each author.

\section{RESULTS}

The case study 'Narrative-based medical writing' has brought out some findings below which are accompanied by language illustrations and observations.

Apparently, all the students' works tended to follow either an essay or a personal diary genre. It should be noted that the writing of each participant deserves careful attention and analysis, and can be used as a phenomenological method of studying the personality of future healthcare professionals.

If at first the students' works resembled articles from popular science magazines, then the descriptions acquired an emotional coloring, in each work the empathy of a suffering person was obvious. The following examples are the most revealing:

Example 1, bronchial asthma, an extract from an essay*,

(beginning): My story is about such an unpleasant disease as bronchial asthma. I have to fight it for the rest of my life, because asthma is incurable. However, it will not bring many problems to your life if you clearly know how to behave in any situation...

(ending): As a result, the doctor diagnosed bronchial asthma of the non-allergic type. I was scared, but later doctor explained to me that this is an ordinary diagnosis and I can live normally. However, I understood only one thing - any irritant can provoke a new attack. It can be cold water, a pungent smell, physical exertion or just severe stress and of course allergens: dust, wool, pollen of plants. We had to get rid of all soft toys and carpets at home, replace feather pillows, hide all books in glass bookcases, because of the dust mites.

Example 2, diabetes mellitus, personal diary entries*,

07.10.2018. I was 12 years old, I studied in 6th grade. In our family, through my mother's line, there is a tendency to diabetes. So my grandmother got sick at the age of sixty, and her brother, too ... Probably, this is a hereditary factor or maybe some kind of strong moral experience.

24.10.2018. ... at night I wake up only at the very last moment. And not long ago at night I had a strong attack. I banged my head against the bed, screamed very loudly and at the same time I had my eyes opened. My husband brought me to consciousness with great difficulty, sweet water helped. By the way, Coca-Cola very quickly increases blood sugar levels.

10.11.2018. What is a honeymoon in the understanding of ordinary people? Honeymoon is the conventional name of the beginning of a joint married life, when young people go on a long-awaited fascinating journey together far away from the whole world. But we, diabetics of the first type are special people. For us, the concept of a honeymoon is a unique period when our pancreas begins to produce insulin again.

(*please note that the authors' spelling and punctuation are generally preserved) 
The authors of the fragments have demonstrated that they are familiar with the topic vocabulary of the diseases, e.g. "bronchial asthma of the non-allergic type", "asthma is incurable", "any irritant can provoke a new attack", "this is a hereditary factor" (about diabetes), "Coca-Cola very quickly increases blood sugar levels".

The works have also shown certain narrative techniques, including a plot and a sequence of events, personification, back story, metaphors and other features typical for narration:

"What is a honeymoon in the understanding of ordinary people? Honeymoon is the conventional name of the beginning of a joint married life, when young people go on a long-awaited fascinating journey together far away from the whole world. But we, diabetics of the first type..."

"For us, the concept of a honeymoon is a unique period when our pancreas begins to produce insulin again."

"My story is about such an unpleasant disease as bronchial asthma. I have to fight it for the rest of my life, because asthma is incurable. However, it will not bring many problems to your life if you clearly know how to behave in any situation..."

"In our family, through my mother's line, there is a tendency to diabetes. So my grandmother got sick at the age of sixty, and her brother, too ..."

The students have used reflective writing techniques. As can be seen from the examples, all students' writings involved argumentation, observation, analysis, exploration and evaluation of what happened and why, e.g.

'For us, the concept of a honeymoon is a unique period...'

'However, I understood only one thing...'

'Probably, this is a hereditary factor'...

Another observation is that the students managed to sincerely act as a patient (use of the $1^{\text {st }}$ person pronouns, dramatic details), the authors have also used their relatives or other real people's experience, which means that they lived through other people's environment. This might be considered a positive result showing empathy development by means of narrative techniques.

One of the most interesting observations we have made is that the authors seem to have difficulties in feelings and emotions description. Their use of emotional vocabulary is rather limited (if any). This might be due to the imaginary situation the case study conditions have put them in. However, even this result can be regarded as positive, since it revealed the difficulty which patients have manifesting their feelings, emotions and personal experience at the physician's consultation.

Speaking about communicative tolerance, it should be mentioned that experts distinguish several types of communicative tolerance:

- situational communicative tolerance - which is manifested as a personal relationship to a specific person;

- typological communicative tolerance - is manifested in relation to personality of a certain type or group of people (separate race, nationality, social group);

- professional tolerance - is manifested between people - participants in relationships in the professional sphere (doctor - patient, nurse - patient, etc.);

- general communicative tolerance. (Boiko, 1996) 
The sphere of our interests was professional communicative tolerance as one of the most significant personal and professional attitudes of a medical worker and possible ways of influencing it. As reported, tolerance can be influenced in the process of education (Boiko, 1996; Kamalova et al., 2019; Torubarova, 2014) To assess the level of communicative tolerance, Boiko test of communicative tolerance measurement was applied (Raigorodsky, 1998) The results obtained demonstrated that the level of communicative tolerance increased in all participants: prior to the study, 9 students showed low and 51 people showed an average level of communicative tolerance; at the end, the level of communicative tolerance of all participants was characterized as high (see Table 1).

Empathy is a core component in the content of medical training. It is manifested as a conscious compassion, sympathy with the current emotional state of another person without losing the sense of the origin of this experience. This attitude is based on high moral standards which a future doctor should possess in this intention to render assistance and support. Experts report on empathy-enhancing educational interventions in undergraduate medical education. (Batt-Rawden et al., 2013; Stepien \& Baernstein, 2006; Cunico et al., 2012; Stebletsova \& Torubarova, 2017) The empathy level was assessed in medical undergraduates before and after the study with the balanced emotional empathy scale (BEES) questionnaire (Mehrabian \& Epstein, 1972), Russian version (Raigorodsky, 1998). It is important to note that the level of empathic manifestations was medium and high after the experiment in comparison with the low and medium, which was observed among the participants before the study (see Table 1).

Table 1. Levels of communicative tolerance and empathic manifestation in medical students participated in the study

\begin{tabular}{|l|c|c|c|c|c|c|}
\hline & \multicolumn{3}{|c|}{ Before } & \multicolumn{3}{c|}{ After } \\
\cline { 2 - 7 } & $\begin{array}{c}\text { low } \\
(\%)\end{array}$ & $\begin{array}{c}\text { medium } \\
(\%)\end{array}$ & $\begin{array}{c}\text { high } \\
(\%)\end{array}$ & $\begin{array}{c}\text { low } \\
(\%)\end{array}$ & $\begin{array}{c}\text { medium } \\
(\%)\end{array}$ & $\begin{array}{c}\text { high } \\
(\%)\end{array}$ \\
\hline $\begin{array}{l}\text { Communicative } \\
\text { tolerance }\end{array}$ & $9(15 \%)$ & $51(85 \%)$ & - & - & - & $60(100 \%)$ \\
\hline $\begin{array}{l}\text { Empathic } \\
\text { manifestations }\end{array}$ & $6(10 \%)$ & $54(90 \%)$ & - & - & $45(75 \%)$ & $15(25 \%)$ \\
\hline
\end{tabular}

\section{CONCLUSION}

The case study 'Narrative-based medical writing' has demonstrated that narrative writing as an integral module of EMP course has multifunctional potential for professional medical training. Being implemented in language practice it can obviously add to improvement of writing skills. Moreover, narrative-based medical writing can positively influence the development of professional skills and attitudes commonly covered by the concept of effective doctor-patient communication.

We may also conclude that although students' stories about the disease written on behalf of patients cannot be strictly attributed to one writing function or style, any narrative-based medical writing inevitably incorporates description, reflection and narration and demonstrates future doctors the language power in constructing a patient's reality, which is, much more than their medical history, develop their communicative skills as an essential instrument in their narrative-based medicine toolkit. 
Therefore, the results obtained clearly demonstrated that a specially organized training activity within an EMP course can contribute to both communicative skills and professional values development crucial for a healthcare practitioner.

\section{REFERENCES}

Bashkin, M. (2015). Communicative Competence of Specialists of Different Professional Groups. Mediterranean Journal of Social Sciences, 6(6 S5), 193. Retrieved from https://www.mcser.org/journal/index.php/mjss/article/view/8545

Batt-Rawden, S. A., Chisolm, M. S., \& Anton, B., Flickenger, T. E. (2013). Teaching empathy to medical students: An updated, systematic review. Academic Medicine, 88(8), 1171-1177. https://pubmed.ncbi.nlm.nih.gov/23807099/

Boiko V.V. (1996). Energy of emotions in communication: look at yourself and others [Energiya emotsii $v$ obshchenii: vzglyad na sebya $i$ drugih]. M.: Information and publishing house "Filin". (In Russian)

Charon R, Hermann N. A sense of story, or why teach reflective writing? Acad Med 2012;87(1):5-7. https://www.ncbi.nlm.nih.gov/pmc/articles/PMC3247912/

Charon R. (2006). Narrative medicine: honoring the stories of illness. New York: Oxford University Press.

Choudhary, A., \& Gupta, V. (2015). Teaching communications skills to medical students: Introducing the fine art of medical practice. International journal of applied \& basic medical research, 5(Suppl 1), S41-S44. https://doi.org/10.4103/2229-516X.162273

Clandinin J, Cave MT, Cave A. Narrative reflective practice in medical education for residents: composing shifting identities. Adv Med Educ Pract. 2010 Dec 20;2:1-7. doi: 10.2147/AMEP.S13241. PMID: 23745070; PMCID: PMC3661238. https://www.ncbi. nlm.nih.gov/pmc/articles/PMC3661238/

Coulehan J. Compassionate solidarity: suffering, poetry, and medicine. Perspect Biology Med 2009;52:585-603. https://pubmed.ncbi.nlm.nih.gov/19855127/

Cunico, L., Sartori, R., Marognolli, O., \& Meneghini, A. M. (2012). Developing empathy in nursing students. Journal of Clinical Nursing, 21, 2016-2025. https://pubmed.ncbi.nlm. nih.gov/22672461/

Kamalova L.A. Zakirova V.G., Putilian N.S. Developing Tolerance In Students Studying At A Multicultural University. The European Proceedings of Social and Behavioural Sciences EpSBS. Conference: IFTE 2019 - 5th International Forum on Teacher Education. P. 755-766. https://doi:10.15405/epsbs.2020.01.82

King, A., \& Hoppe, R. B. (2013). "Best practice" for patient-centered communication: a narrative review. Journal of graduate medical education, 5(3), 385-393. https://doi.org/ 10.4300/JGME-D-13-00072.1

Mercer, S. W., \& Reynolds, W. J. (2002). Empathy and quality of care. The British journal of general practice: the journal of the Royal College of General Practitioners, 52 Suppl(Suppl), S9-S12. https://www.ncbi.nlm.nih.gov/pmc/articles/PMC1316134/pdf/ 12389763.pdf

Oxford English Dictionary. - https://www.lexico.com/definition/narrative

Oxford learner's dictionaries. - https://www.oxfordlearnersdictionaries.com/

Raigorodsky, D. Y. (Ed.). (1998). Practical psychodiagnostics: methods and tests [Practical psychodiagnostic: Techniques and tests]. Samara: BAHRAH-M (In Russian) 
Shapiro J, Narrative medicine and narrative writing. Fam. med 2012;44(5):309-11. https://pubmed.ncbi.nlm.nih.gov/23027111/

Sidorenko L.I., Abakumova I.V., Pirumyan A.A. (2019). Research of communicative tolerance of psychiatrists and neurologists. World of Science. Pedagogy and psychology, [online] 2(7). Available at: https://mir-nauki.com/PDF/68PSMN219.pdf (in Russian)

Stebletsova A. \& Torubarova I., (2017). Empathy development through ESP: a Pilot Study. Journal of Educational Cultural and Psychological Studies (ECPS Journal), 16, 237-49. https://www.ledonline.it/index.php/ECPS-Journal/article/view/1252

Stepien, K. A., \& Baernstein, A. (2006). Educating for empathy: A review. Journal of General Internal Medicine, 21(5), 524-530. https://pubmed.ncbi.nlm.nih.gov/16704404/

Torubarova I.I. (2014). Communicative tolerance as a professionally significant feature of the medical student personality. Vestnik VSTU. 10(3.2):70-73. (In Russian). https://www.elibrary.ru/download/elibrary_21676014_68694131.pdf

Zaharias G. (2018). What is narrative-based medicine? Narrative-based medicine 1. Canadian family physician Medecin de famille canadien, 64(3), 176-180. https://www.ncbi.nlm. nih.gov/pmc/articles/PMC5851389/

Чудаков А. П. Повествование // Краткая литературная энциклопедия / Гл. ред. А. А. Сурков. — М.: Сов. энцикл., 1962-1978. Т. 5: Мурари - Припев. — 1968. - Стб. 813. http://feb-web.ru/feb/kle/KLE-abc/ke5/ke5-8133.htm 